\title{
Relationship between dependence on modern communication tools and psychological well-being in students \\ Narges Afradi ${ }^{1}$, Bibiaghdas Asghari ${ }^{2}$, Farzaneh Mikaeili Manie ${ }^{3}$
}

\author{
Journal of Research \& Health \\ Social Development \& Health Promotion \\ Research Center \\ Vol. 7, No. 1, Jan \& Feb 2017 \\ Pages: 637- 646. \\ DOI: 10.18869/acadpub.jrh.7.1.637 \\ Original Article
}

1. School of Literature and Humanities, Islamic Azad Uiversity Birjand Brach, Birjand, Iran

2. Correspondence to: Department of Social Science, School of Humanities, Islamic Azad University Gonabad Branch, Gonabad, Iran

Email: a_asghari2002@yahoo.com

3. Department of Educational Psychology, School of Literature and Humanities, Orumieh University, Orumieh, Iran

Received: 2 Jan 2016

Accepted: 2 Mar 2016

How to cite this article: Afradi N, Asghari B, Mikaeili Manie F. The survey of relationship between dependence on modern communication tools and psychological wellbeing. J Research \& Health2017; 7(1): 637646.

\begin{abstract}
Nowadays due to technological advance and its direct impact on the quality of human life, addressing the issue of health and its determinants is very important. Maintaining public health is one of the most fundamental issues in each community. The aim of the study was to survey relationship between dependence on modern communication tools (internet and mobile phones) and psychological well-being. 300 university students was selected according to cluster sampling method. The questionnaires were distributed to the students and 141 completed questionnaires were collected. The Young Internet addiction test and mobile phone addiction index were used to measure the predictor variables and the Ryff psychological well-being scale was used for the criterion variable. Multiple regression analysis gave a multiple correlation coefficient (R) of 0.347 and adjusted coefficient of determination (R2) of 0.120. According to the calculated Beta values, the variable of dependence on mobile phones with the value of 0.196 showed the greatest power for explaining the autonomy component. The results showed a significant negative relationship between independent variables, i.e. dependence on the Internet and mobile phones, and dependent variables, i.e. psychological well-being and its components.
\end{abstract}

Keywords: Communication, Dependency, Media, Psychological Wellbeing

\section{Introduction}

Nowadays due to technological advance and its direct effect on quality of human life, addressing the issue of health and its determinants is very important. Maintaining public health is one of the most fundamental issues in each community. The prevalence of high risk behaviors among different segments is one of the most serious threats to health which in recent years has been considered by health organizations, law enforcement and social policy makers. Although none of segments of society is immune to the consequences of healththreatening behaviors that some social and age groups include adolescents and young adults are at higher risk. Studies have shown that there is relationship between using mobile phone 
and aggression, smoking and suicidal tendency. Also, uncontrolled use of computer puts at risk physical, social and emotional development of young adults. The media systems dependency theory was proposed by Sandra Ball-Rokeach and Melvin De Fleur in 1976. According to this theory, there is permanent relationship between audience, media and social systems. According to Fleur, audience uses media because they have vital need of information for decision making. The requirements include understanding social environment, accompanying social norms and away from social reality. In term of recognition, media has more power of shaping, changing and highlighting attitudes because audience depends on media at time of decision making. On the other hand, media emotionally can inspire various emotions such as fear, anxiety and joy in their audience. Such media are capable of making significant changes in audience's behaviors towards measures that the audience normally does not involve in them [1].

Youth mental health is important issue in psychology and sociology. Today, students engaged their mobile phones and surfing the internet and communicate with each other for fun in leisure time. Many studies indicate high prevalence of these activities in society. Results of descriptive study showed that $17.7 \%$ of nursing students were addicted to Internet [2]. In another study, the prevalence of dependence on mobile was $0.9 \%$. In addition, excessive, problematic usage of mobile phones is correlated with aggression, smoking, suicidal tendencies, low self-esteem, isolation, and loneliness [3]. In another study, the individuals who referred to coffee-nets in Kermanshah were investigated. The findings showed that Internet addiction can lead to psychological, social, educational and occupational problems. Psychoticism and anxiety variables were the predictors of Internet addiction [4]. Another research studied mobile usage among students and showed that excessive usage of mobile phones increased loneliness and also decreased social support [5]. The effects of texting and Bluetooth application on high school students were examined in study and it was found that students use the cell-phone features to communicate with their friends and fill their leisure time. Dependence on cell-phone is related to increased unhealthy social relationships and academic failure [6]. Multidimensional impacts of mobile phones and the Internet on culture, policies, and psychology of human are not studied thoroughly despite the widespread usage of these multifaceted tools in society.

A review of literature revealed that majority of previous studies targeted personal and social problems except few studies that investigated well-being. Indeed, the relationship between dependence on modern communication tools (Internet and mobile phones) and psychological well-being has not been studied well. The present study mainly aimed to examine the relationship between dependence on modern communication tools (Internet and mobile phone) and psychological well-being. The second aim of study determine the relationship of dependence on modern communication tools (Internet and mobile phone) with psychological well-being and determine the relationship of dependence on modern communication tools (mobile phone) with six components of psychological well-being. Theoretical model of the study is as follows (Figure 1).

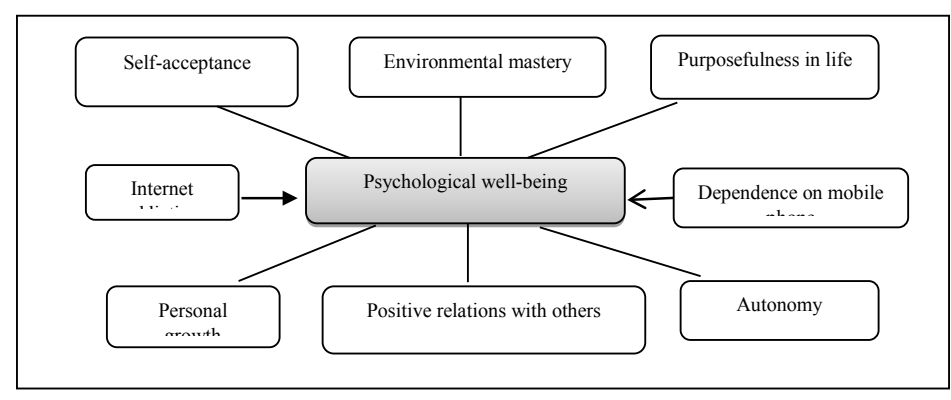

Figure 1 Exploratory-analytical model 
According to observation exploratory researchers, aim of the present study must be considered in cognitive and applied perspectives. In the cognitive aspect, decreased social relations and social isolation, along with increased loneliness, depression, conflicts and confusion in human moods and emotions as well as decreased familial relationships and social interactions are the most probable consequences of excessive usage of mobile phones and the Internet in some cases. According to the applied perspective, parents and public people are concerned about Internet addiction and dependence on mobile phones as two common problems in modern societies. Mean Internet usage was higher in boy high school students than girl high school students in Semnan. A positive significant correlation was found between the Internet usage and neuroticism subscale. On the other hand, negative significant correlation was found between Internet usage and extroversion [7]. In another study, relationship between public health and excessive usage of mobile phones was investigated among 782 students. A significant positive relationship was found between public health dimensions and excessive usage of mobile phones [8]. It was also found that Internet addiction had significant positive relationship with clinical variables of depression, anxiety, stress and social phobia. In the other words, individuals with dependence on the Internet are less willing to be socialized and communicate with their peers. In fact, extreme dependence on virtual world is related with detachment from the real world and physical inactivity; it decreases happiness and social interaction and leads to depression, anxiety, and social isolation [9]. In previous study, the adjustment construct could predict components of positive relations with others and selfacceptance. Moreover, conscientiousness trait predicted the independence component. In addition, neuroticism characteristic predicted the components of independence, positive relations with others, personal growth and purposefulness in life. Self- acceptance construct predicted the components of environmental mastery, independence, personal growth, purposefulness in life and self-acceptance. The Beta values showed that extraversion predicted all the six components of well-being [10]. In another study, extroversion had significant relationship with communicating with others, self-acceptance, autonomy and environmental mastery [11]. In recent foreign studies, dependence on mobile phones and excessive usage of cell phones had negative psychological effects on students [12]. The results of master thesis indicated that smart phone addiction had significant negative relationship with faceto-face relations. On the other hand, smart phone addiction had significant positive relationship with absence in society [13]. The aim of the present study was to survey the relationship between dependence on modern communication tools (Internet and mobile phones) and psychological well-being.

\section{Method}

It was cross-sectional and correlational study. The statistical population consisted of 4600 University students in Gonabad city, Northeast of Iran, in 2015. Among them, 300 students were selected by using Morgan table according to cluster sampling method (clusters included branches of medical sciences, humanities and technical and engineering sciences). Each student was asked to fill out three scales. The questionnaires were distributed to all participants. In total, 141 completed questionnaires were collected. In this study, Young Internet addiction test, mobile phone addiction index was used to measure the predictor variables.

Young Internet Addiction Test: Internet addiction test (IAT) was developed by Young in 1998 and is validated questionnaire which has shown good psychometric properties in Iranian society based on research of Alavi et al [14] employed several methods in their study to calculate validity of Young's IAT. The IAT has 20 items that measured on a five-point Likert scale. The total score ranges from zero to one hundred in which 
the higher score represents greater reliance on Internet. Based on scores, severity of problems is determined excessive use of Internet for person. Young's instruction 1998 was used to interpret results. According to instruction, score in range of 0-39 indicates normal users, 40-69 at-risk users, and 70-100 addicted users. The content validity of test was confirmed by presenting it to 10 experts ( 5 psychiatrists and 5 psychologists). Correlation between the scores of Young's IAT and scores of Young's Diagnostic Questionnaire for Internet addiction (YDQ) was assessed to analyze convergent validity and coefficient of 0.5 was obtained $\mathrm{p}<0.05$ ). Factor analysis of varimax rotation method was used to evaluate construct validity. The scores could explain $56 \%$ of the total variance. The factor loadings were $40 \%$ to $76 \%$ for social problems (including items 5, 9, 10, $15,18,19,21$, and 22$), 47 \%$ to $76 \%$ for effect on performance (including items 11, 13,16 , 20 , and 21 ), $40 \%$ to $73 \%$ for loss of control (including items 1, 2, 7, 12, 14, 15, and 17), $63 \%$ to $89 \%$ for abuse of chat rooms (including items 3,4 , and 8 ), and $50 \%$ to $80 \%$ for neglect of profession and education duties (including items 2, 6, and 9). Plotting eigenvalue and factor loading model also proposed 5 factors. In order to determine the sensitivity and specificity of the questionnaire, psychiatric interview was used in addition to the test implemented for the diagnosis of Internet addiction. For this purpose, all participants were interviewed. According to the psychiatrist, 30 participants from sample group were diagnosed with Internet addiction. Internet addiction test sensitivity was $80 \%$ and its specificity was about $78 \%$. In order to determine the cut-off point, upon obtaining the sensitivity and specificity, data were analyzed by Receiver operating characteristic (ROC) curve in SPSS 16. Based on the obtained results on the amount of accuracy, $89 \%$ of diagnostic cases had been diagnosed correctly $(p<0.001)$. The cutoff point was estimated to be 46 . The test's internal consistency index for Cronbach's alpha coefficient was obtained 0.88 . Cronbach's alpha for the first, second, third, fourth and fifth factors were $0.81,0.73,0.75,0.74$, and 0.62 , respectively. Classification methodology was used to determine the internal validity of the questionnaire which was $0.72(\mathrm{p}<0.01)$. Retest technique was used to determine the external validity that generated the correlation coefficient $082(\mathrm{p}<0.01)$. In study by Young et al, the internal validity of questionnaire was higher than 0.92 and the reliability of the questionnaire by retest technique was also significant [14]. Widianto and McMoRan in their study stated that psychometric properties of the test were very satisfactory. Moreover, they obtained six factors including salience, excessive use, neglecting work, lack of control, social problems and impact on performance on the basis of analysis of factors. All of them indicate internal consistency and validity [15]. Khazaei et al. obtained the coefficient of 0.92 for test reliability by a case study on 30 students [16]. The reliability of the test has been confirmed based on Cronbach's alpha with 0.883 . In this research, the Cronbach's alpha coefficient was obtained 0.941 .

Mobile Phone Addiction Index (MPAI): The first part of Mobile Phone Addiction Index included demographic characteristics and how mobile phone is in use. The second part consisted of 20 questions about the dependence on cell phone. The scale comprised three dimensions including endure deprivation (7 items), dysfunction of life (6 items), and compulsion- insisted (7 items). Every item has four options which include very high, high, low and very low. The respondents are defined as phone addicts (score $\geq 70$ ), severe users (score 63-70) and moderate users (score $<63$ ).

Ryff's Psychological Well-Being Scale (PWB): was used to measure criterion variable in model was developed by Ryff and colleagues. The Psychological Well-Being Scale was designed at University of Wisconsin by Carol Ryff in 1989. This scale has short form and also long version. This scale in this study has 54 items. Participants respond to items on a six points scale (strongly disagree to strongly agree). Each component is measured by 9 items. Psychological well-being scale is 
composed of six components of self-acceptance, environmental mastery, positive relations with others, personal growth, autonomy and purposefulness in life. The independent variables were Internet addition and dependence on mobile phone. The dependent variable was psychological well-being. In this study, alpha coefficients were obtained as follows: selfacceptance 0.72 , positive relations with others 0.52 , autonomy 0.31 , environmental mastery 0.51 , purposefulness in life 0.54 , personal growth 0.45 , Internet addiction 0.941 , and dependence on mobile phone 0.797 .

Ryff Scales of psychological well-being

Table 1 The scoring of psychological well-being scale components in the

\begin{tabular}{lc} 
Ryff model & Items \\
\hline Component & $4-9-14-23-28-31-43-48-51$ \\
Self-acceptance & $8-13-22-27-30-33-38-42-46$ \\
Purposefulness in life & $3-18-21-26-37-41-45-50-54$ \\
Personal growth & $2-7-12-17-20-29-36-49-53$ \\
Environmental mastery & $6-11-16-19-25-35-40-44-52$ \\
Autonomy & $1-5-10-15-24-32-34-39-47$ \\
Positive relations with others &
\end{tabular}

Table 2 The results of Cronbach's alpha for variables

\begin{tabular}{lc|c}
\hline Variables & Cronbach's alpha \\
\hline Internet addiction & \multicolumn{2}{c}{0.941} \\
Mobile dependence & \multicolumn{2}{c}{0.797} \\
Psychological well-being & \multicolumn{2}{c}{0.867} \\
\hline Self-acceptance & 0.72 & \\
Purposefulness in life & 0.54 & \\
Personal growth & 0.45 & $\begin{array}{l}\text { Components } \\
\text { of psychology } \\
\text { well-being }\end{array}$ \\
Environmental mastery & 0.51 & \\
Autonomy & 0.61 & \\
\hline Positive relations with others & 0.52 & \\
\hline
\end{tabular}

\section{Results}

The socio-demographic data of sample reveals that gender distribution of respondents was $45.4 \%$ female and $53.2 \%$ male. $52.2 \%$ of participants were in age group of 18-22 years, $22 \%$ in $23-26$ years, and $5 \%$ in $36-45$ years. $36.9 \%$ of respondents were students at Islamic Azad University, 27.7\% at Gonabad University of Medical Sciences, and 35.5\% at Payam Noor University. $50.4 \%$ of respondents were medical sciences students, 30\% Humanities students and $10.6 \%$ engineering students.

The results showed that the majority of participants $(83 \%)$ were mobile phone users for less than 10 years. The average number of daily received calls was less than 10 calls and number of daily outgoing calls was 1 to 5 calls. Duration of each call was less than 5 minutes in the half of mobile phone users. 
More than half of them received and sent less than 10 text messages per day. All respondents used their mobile phones for talking. In addition, they used their mobile phones mostly for sending texts, playing music, transferring by Bluetooth, watching videos, recording by camera, playing games, surfing the Internet and using the Global Positioning System (GPS). More than $50 \%$ of respondents take charge less than $55 \$$ per month.

SPSS 16 software was used to analyze data in inferential statistics. Pearson correlation coefficient, multiple regression technique were used to test research's hypothesis

Table 3 The mean and standard deviation of dependence on mobile phones and internet addiction and psychological well-being

\begin{tabular}{lcccc}
\hline Variables & Minimum & Maximum & Mean & Standard deviation \\
\hline Psychological well-being & 138 & 288 & 215 & 25.31 \\
Purposefulness in life & 15 & 51 & 7.36 & 35.6 \\
Autonomy & 19 & 47 & 58.33 & 69.5 \\
Self-acceptance & 17 & 84 & 39.35 & 68.8 \\
Personal growth & 18 & 49 & 14.35 & 12.6 \\
Environmental mastery & 17 & 51 & 94.35 & 36.6 \\
Relations with others & 10 & 52 & 73.35 & 22.7 \\
Internet addiction & 20 & 94 & 90.46 & 73.17 \\
Dependence on mobil & 23 & 71 & 49.31 & 69.10 \\
phone & & & &
\end{tabular}

Table 4 The results of pearson correlation coefficient test for independent variables and dependent variable (psychological well-being)

\begin{tabular}{|c|c|c|c|c|c|}
\hline \multicolumn{6}{|c|}{ The relation of Internet addiction and dependence on mobile phone to psychological well-being } \\
\hline Independent variable & $\mathrm{R}$ & df & p-value & $\mathrm{CR}$ & Result \\
\hline Internet addiction & -0.358 & 139 & 0.000 & 0.321 & Verified \\
\hline Dependence on mobile phone & -0.277 & 139 & 0.001 & 0.254 & Verified \\
\hline \multicolumn{6}{|c|}{ The relation of Internet addiction and dependence on mobile phone to self-acceptance } \\
\hline Independent variable & $\mathrm{R}$ & df & p-value & $\mathrm{CR}$ & Result \\
\hline Internet addiction & -0.327 & 139 & 0.000 & 0.321 & Verified \\
\hline Dependence on mobile phone & -0.14 & 139 & 0.098 & 0.245 & Rejected \\
\hline \multicolumn{6}{|c|}{ The relation of Internet addiction and dependence on mobile phone to personal growth } \\
\hline Independent variable & $\mathrm{R}$ & df & p-value & $\mathrm{CR}$ & Result \\
\hline Internet addiction & -0.162 & 139 & 0.056 & 0.164 & Rejected \\
\hline Dependence on mobile phone & -0.179 & 139 & 0.03 & 0.164 & Verified \\
\hline \multicolumn{6}{|c|}{ The relation of Internet addiction and dependence on mobile phone to purposefulness in life } \\
\hline Independent variable & $\mathrm{R}$ & df & p-value & $\mathrm{CR}$ & Result \\
\hline Internet addiction & -0.242 & 139 & 0.004 & 0.230 & Verified \\
\hline Dependence on mobile phone & -0.238 & 139 & 0.004 & 0.230 & Verified \\
\hline \multicolumn{6}{|c|}{ The relation of Internet addiction and dependence on mobile phone to autonomy } \\
\hline Independent variable & $\mathrm{R}$ & df & p-value & $\mathrm{CR}$ & Result \\
\hline Internet addiction & -0.358 & 139 & 0.000 & 0.321 & Verified \\
\hline Dependence on mobile phone & -0.227 & 139 & 0.000 & 0.321 & Rejected \\
\hline \multicolumn{6}{|c|}{ The relation of Internet addiction and dependence on mobile phone to relations with others } \\
\hline Independent variable & $\mathrm{R}$ & df & p-value & $\mathrm{CR}$ & Result \\
\hline Internet addiction & -0.358 & 139 & 0.000 & 0.321 & Verified \\
\hline Dependence on mobile phone & -0.056 & 139 & 0.492 & 0.164 & Rejected \\
\hline \multicolumn{6}{|c|}{ The relation of Internet addiction and dependence on mobile phone to environmental mastery } \\
\hline Independent variable & $\mathrm{R}$ & df & p-value & $\mathrm{CR}$ & Result \\
\hline Internet addiction & -0.372 & 139 & 0.000 & 0.321 & Verified \\
\hline Dependence on mobile phone & -0.177 & 139 & 0.03 & 0.164 & Verified \\
\hline
\end{tabular}


According to Table 4, correlation coefficients of psychological well-being with dependence on mobile phone and Internet addiction were -0.358 and -0.277 respectively which were higher than critical value. Research's hypothesis was assessed by comparing coefficient for R Pearson with critical value for Pearson coefficient. The psychological wellbeing showed indirect significant relationship with Internet addiction and dependence on mobile phone at $99 \%$ confidence level. Also the relationships of independent variables with all six components of psychological well-being were examined. According to the correlation coefficients, there was significant relationship between self-acceptance and Internet addiction at $99 \%$ confidence level and no significant relationship between self-acceptance and dependence on mobile phone was observed. No significant relationship was also found between personal growth and Internet addiction. On the contrary, there was significant relationship between personal growth and dependence on mobile phone at $95 \%$ confidence level.

An indirect significant relationship was found between purposefulness in life and Internet addiction at $99 \%$ confidence level. The correlation coefficient between two variables of purposefulness in life and dependence on mobile phone was -0.238 so the research's hypothesis was confirmed. There was negative significant relationship between purposefulness in life and dependence on mobile phone at $99 \%$ confidence level. The correlation coefficient between autonomy and dependence on mobile phone was obtained as -0.227 . Therefore, no significant relationship was found between autonomy and dependence on mobile phone. The correlation coefficient showed negative significant relationship between the variable of positive relations with others and Internet addiction at $99 \%$ confidence level. However, correlation coefficient between positive relations with others and dependence on mobile phone was -0.056 . Therefore, no significant relationship was found between latter variables.

The correlation coefficient indicated negative significant relationship between Internet addiction and environmental mastery at $99 \%$ confidence level while there was significant indirect relationship between environmental mastery and dependence on mobile phone at 95\% confidence level.

Multiple regression technique was used to evaluate direction and intensity of relationship between the dependent and independent variables.

The results of multiple regression analysis gave multiple correlation coefficient (R) value of 0.347 and adjusted coefficient of determination (R2) value of 0.120 . In the other words, $12 \%$ of variance of psychological well-being was explained by the research variables. Beta values were also calculated as follows.

Table 5 The regression coefficients of independent variables to dependent variables of Internet addiction and dependence on mobile phone

\begin{tabular}{|c|c|c|c|c|c|c|}
\hline \multirow{2}{*}{ Variables in the equation } & \multirow{2}{*}{ Variable } & \multicolumn{2}{|c|}{$\begin{array}{c}\text { Non-standardized } \\
\text { coefficient }\end{array}$} & \multirow{2}{*}{$\begin{array}{c}\text { Standardized } \\
\text { coefficient }\end{array}$} & \multirow{2}{*}{$\mathrm{T}$} & \multirow{2}{*}{ p-value } \\
\hline & & $\mathrm{B}$ & SE & & & \\
\hline Relations with others & \multirow{6}{*}{$\begin{array}{l}\text { Dependence on } \\
\text { mobile phone }\end{array}$} & 0.037 & 0.059 & 0.054 & 0.626 & 0.532 \\
\hline Environmental mastery & & -0.030 & 0.050 & 0.050 & -0.596 & 0.552 \\
\hline Personal growth & & 0.080 & 0.051 & 0.139 & 1.562 & 0.121 \\
\hline Self-acceptance & & -0.021 & 0.070 & -0.026 & -0.306 & 0.760 \\
\hline Autonomy & & 0.105 & 0.047 & 0.196 & 2.218 & 0.028 \\
\hline Purposefulness in life & & 0.103 & 0.052 & 0.173 & 1.989 & 0.049 \\
\hline Relations with others & \multirow{6}{*}{ Internet addiction } & 0.128 & 0.035 & 0.315 & 3.626 & 0.000 \\
\hline Environmental mastery & & 0.127 & 0.030 & 0.354 & 4.185 & 0.000 \\
\hline Personal growth & & -0.039 & 0.031 & -0.112 & -1.254 & 0.212 \\
\hline Self-acceptance & & 0.155 & 0.042 & 0.317 & 3.689 & 0.000 \\
\hline Autonomy & & -0.027 & 0.028 & -0.085 & -0.960 & 0.339 \\
\hline Purposefulness in life & & -0.065 & 0.031 & -0.180 & -2.069 & 0.040 \\
\hline
\end{tabular}


Table 5 indicated that maximum Beta value in case of dependence on mobile phone variable was obtained as 0.196 that means variable was the most capable of explaining variance of autonomy variable. The Beta values for purposefulness in life and personal growth were 0.173 and 0.139 respectively. Hence, variances of these two variables were explained by dependence on mobile phone. However, amount of variance of autonomy was explained by dependence on mobile phone was higher than amount of explanation of purposefulness in life and personal growth. The maximum Beta value in case of Internet addiction variable was obtained as 0.354 which means that variable has the most capable explaining variance of environmental mastery. In addition, Beta values for self-acceptance and relations with others were respectively 0.317 and 0.315 . Therefore, majority of variances of these two variables were explained by Internet addiction variable. However, the amount of variance of environmental mastery was explained by Internet addiction was higher than those of selfacceptance and relations with others.

\section{Discussion}

The present study mainly aimed to evaluate relationship between dependence on modern communication tools (Internet and mobile phone) and psychological well-being. The results showed that dependence on mobile phone and Internet addiction had significant inverse relationships with psychological wellbeing. In similar studies, excessive usage of mobile phone and Internet addiction had been proven to have negative significant relationships with public health dimensions $[3,8,12,17]$. Also the relationships of independent variables (dependence on mobile phone and Internet addiction) with one of six components of psychological well-being were examined. In this regard, significant inverse relationships were found between following variables: dependence on mobile phones and personal growth; dependence on mobile phones and purposefulness in life; Internet addiction and purposefulness in life.
A significant negative relationship was found between Internet addiction and relations with others. Dependence on mobile phone and Internet addiction had negative significant relations to environmental mastery. Some other studies have showed similar results $[2,7,9,10,13]$. However, no significant relationships were found between following variables: dependence on mobile phone and self-acceptance, personal growth and Internet addiction, dependence on mobile phone and relations with others.

In general, we can argue that people who have high psychological well-being feel less depression, anxiety and helplessness and they engage more in high risk behaviors. Thus, dependence on mobile phone and Internet addiction in people are rare. Heavy usage of mobile phones especially sending and receiving texts among youth can cause serious fear and anxiety so that some users have a lot of preoccupation about answers and their quality. These activities may lead to dysregulation of sleep and disruption of daily tasks. There is significant positive relationship between impulsivity and loneliness and phone usage rate.

Since loneliness is associated with some psychological characteristics such as impulsivity, aggression, introversion, embarrassment, shame, low self-esteem external documents successfully. Considering that both impulsivity and loneliness in adolescents and young adults reach their peaks, therefore these two features have good correlation each other in this age group When these two features simultaneously were in young as a result individual's motivation rises for use of communication technologies such as mobile phones to eliminate tension and loneliness. Therefore both variables can be good predictor of impulsivity and loneliness. Excessive and unnecessary use of mobile phones creates tension and mental distress in the user.

The results of the present study were compared with previous studies. It was found that dependence on mobile phone 
affects different aspects of psychological wellbeing. Dependence on mobile phone causes depression, failure and loneliness. It also can lead to disrupted profession and daily living (due to frequent calls, text messages and surfing the Web and forums), impulsivity and loneliness, less social support, sleep disorder, daily tasks disruption, mental distress, unhealthy relationships and academic failure.

\section{Conclusion}

In summary, Internet addiction is associated with components of psychological wellbeing. Excessive dependence on virtual world is related to detachment from the real world as well as physical inactivity which decrease happiness and social interaction and cause depression, anxiety and social isolation. Internet addicts feel less obligation to society, family, jobs, friends, etc. which in turn can increase possibility of deviant behaviors factors. Since the study was conducted just in Gonabad city so we recommend similar studies in other cities of Iran in order to obtain clear image of relationship between dependence on modern communication tools (the Internet and mobile phone) and psychological well-being by comparing findings. Similar studies should also be done on other segments of the society (students, staff and employees). According to significance of relationship between dependence on modern communication tools and psychological well-being, it is recommended that policy maker should plan for training programs about use of modern communication tools. It is essential to design effective interventions and appropriate training strategies in terms of mobile phone usage for students due to their susceptibility to adverse effects of dependence on mobile phone.

\section{Contribution}

Study design: BA, FM

Data Collection and Analysis: NA

Manuscript preparation: BA

\section{Acknowledgements}

The author would like to state his appreciation of the cooperation and assistance of authorities and staff of the research department of the Islamic Azad University Birjand Branch, as well as all students who participated in this study.

\section{Conflict of Interest}

"The authors declare that they have no competing interests."

\section{Funding}

The author (s) received financial support for the research from the research deputy of Tarbiat Modares University.

\section{References}

1- DeFleur ML, Ball-Rokeach S. Theories of mass communication. 5th Ed. New York: Longman; 1989.

2- Kiany T, Fallahi Khoshknab M, Dalvandi A, Hosaini $\mathrm{M}$, Nourozi K. Internet addiction and its related factors among nursing students in Tehran University of Medical Sciences in 2013. Journal of Nursing Education2014; 2(4): 50-62.

3- Khazaee T, Saadatjoo A, Shabani M, Senobari M, Baziyan M. Prevalence of mobile phone dependency and its relationship with students, self-esteem. Journal of Knowledge \& Health2014; 8(4): 156-62.

4- Kalhornia Golkar M, Saffarnia M, Amirpoor B. Examine the relationship between internet addiction and mental health client's internet cafe in of Kermanshah city. 6th international congress on child and adolescent psychiatry. September 17-19, 2013; Tabriz University of Medical Sciences. p:1-8.

5- Mansourian M, Solhi M, Adab Z, Latifi M. Relationship between dependence to mobile phone with loneliness and social support in University students. Razi Journal of Medical Sciences2014; 21(120):1-8.

6- Panahi Y, Faraji R, Batvaz H. Dependence on mobile phone and psycho-social trauma in children: Effects of SMS and Bluetooth. The first congress of cyber space and social problems. December 9, 2012; Tehran, ministry of labor, cooperation and social welfare of the Islamic Republic pdf ran. p:1-11.

7- Baidokhti A, Rahaee F, Daneshzadeh F. Anticipating the characteristic features of the learners according to their dependency on novel internet technology and communication. The first congress of cyber space and social problems December 9, 2012; Tehran, ministry of labor, cooperation and social welfare of the Islamic Republic of Iran. p: 1-15.

8- Yaseminejad P, Golmohammadian M, Yoosefi N. The study of the relationship between cell-phone use 
and general heath in students. Knowledge \& Research in Applied Psychology2012; 13(1): 60-72.

9- Jafari N, Fatehizadeh M. Investigation of the relationship between internet addiction and depression, anxiety, stress and social phobia among students in Isfahan University. Scientific Journal of Kurdistan University of Medical Sciences2012; 17(4): 1-9.

10- Dastjerdi R, Farzad V, Kadivar P. The role of five big personality factors in predicting psychological well-being. Journal of Birjand University of Medical Sciences2011; 18(2): 126-33.

11- Ahmadian H, Joumhouri F, Ahadi H, Farrokhi N. Develop and test the relation between personality, psychological needs and psychological well-being. Magazine Psychological Achievements2011; 4 (1): 1-18.

12- Jones T. Students' Cell Phone Addiction and Their Opinions. The Elon Journal of Undergraduate Research in Communications2014; 5(1): 74-80.

13- Casey Bian M. Linking psychological attributes to smart phone addiction, face-to-face communication [dissertation]. MA. In New Media: The Chinese University of Hong Kong 2012; pp: 44.

14- Alavi SS, Eslami M, Maracy MR, Najafi M, Jannatifard F, Rezapour H. Psychometric properties of Young Internet addiction test. Journal of Behavioral Sciences2010; 4(3): 183-9.

15- Khazaei T, Saadatjoo A, Ahabani M, Sanobari M, Bazian M. The analysis of prevalence of dependence on mobile and its relationship with students' self-esteem. Journal of Knowledge \& Health2013; 8(4): 162-56.

16- Ghasemzadeh L, Shaahraray M, Moradi A. Evaluation of rates of Internet addiction and its relationship with loneliness and self-esteem in male and female high school students. Education and Training2010; 89: 41-68.

17- Michaeli Manee F. The Study of Ryff's Psychological Well-being Scale Factorial Structure between Urmia University Students. Journal of Psychology2010; 5(18): 143-67. 